\title{
The Impact of New Rural Cooperative Insurance on Migrant Workers' Consumption: Empirical Analysis Based on China Migrants Dynamic Survey
}

\author{
Juanjuan Huang ${ }^{1}$, Jinhong Jiang ${ }^{1} \&$ Qishui $\mathrm{Chi}^{1}$ \\ ${ }^{1}$ School of Business, Shantou University, Shantou, China \\ Correspondence: Qishui Chi, School of Business, Shantou University, Shantou 515063, Guangdong, China. Tel: \\ 86-158-1526-2450. E-mail: qschi@stu.edu.cn
}

Received: March 3, 2020

Accepted: April 13, 2020

Online Published: June 16, 2020

doi:10.5430/rwe.v11n3p36

URL: https://doi.org/10.5430/rwe.v11n3p36

\begin{abstract}
Based on the data from the National Health Commission of China, this paper analyzes the impact of the new rural cooperative medical insurance on the household consumption of migrant workers by using the ordinary least squares method and the propensity score matching method. The study found that the average annual per capita consumption of participating migrant workers decreased by $3.5 \%$, and the influence of NCMS on the consumption of different groups of migrant workers was significantly different, among which, the negative impact of consumption of low-income group, young group and group with high degree of urban integration is significant. Based on the analysis of the consumption mechanism of NCMS and the heterogeneity of migrant workers, this paper puts forward some differentiated insurance policy suggestions.
\end{abstract}

Keywords: new rural cooperative medical insurance, migrant workers consumption, heterogeneity

\section{Introduction}

Consumption is a key driver of economic growth and a reflection of people's needs for a better life. The report of the Nineteenth National Congress of the Communist Party of China (CPC) explicitly called for "improving the institutional mechanism for promoting consumption and enhancing the fundamental role of consumption in economic development". At present, China's people's saving rate is high and consumption is low. How to further stimulate the consumption potential of residents, is still a hot issue today. Most existing studies explaining insufficient consumption based on the precautionary savings theory (Leland, 1968; Zeldes, 1989), which proposed that risk-averse consumers make precautionary savings due to the uncertainty of future income; On this basis, Hubbard (1995) pointed out that, in addition to the uncertainty of future income, events affecting future consumption would also motivate households to make preventive savings. So, in theory, basic health insurance could drive the welfare gains (Bairoliya, Canning, Miller, \& Saxena, 2018) and boost consumption by shielding people from risk and reducing future uncertainty. At present, China's basic medical insurance is in the stage of reform, and the medical security system is still in the process of improvement. Therefore, it is of great significance to study the basic medical insurance to stimulate the growth of residents' consumption and promote the high-quality growth of China's economic.

In 2019, China's residents' income and consumer spending have grown steadily, but per capita consumption expenditure of rural residents was less than half of the per capita consumption expenditure of urban residents, therefore, raising the consumption of rural residents can effectively boost economic growth. Since China's economic reform and open, the transfer of labor force from rural to urban is the inevitable trend in the development of socialist market economy. According to the data of the National Bureau of Statistics, the total number of migrant workers in China has continued to rise in recent years, from 269 million in 2013, to 291 million in 2019. As the main force of consumption of rural residents, its huge scale determines its important position in economy. Migrant workers have low disposable income, high liquidity, higher degree of worry about sudden expenditure, more awareness of savings, their consumption demand has not been really released, so, there is greater room for development.

In the aspect of medical insurance, compared with urban residents, residents holding agricultural registered permanent residence have a lower level of security; Meanwhile, the security level of floating population is 
significantly lower than that of local population because of factors such as household registration restriction (Zhou, 2015), so migrant workers, who are both migrants and rural residents, cannot get effective guarantee in medical insurance. In recent years, in order to solve the problem of poverty caused by illness, China has carried out a new rural cooperative medical insurance system (hereinafter referred to as the NCMS), which focuses on the pooling of serious illness, and raises funds by means of individual payment, collective support and government subsidy. The aim of NCMS is to provide medical assistance and relief to farmers, which is the first time Chinese government has made a large-scale investment in solving the basic medical and health problems of farmers and has filled the vacancy of basic medical insurance in rural areas. By the end of 2014, NCMS had basically covered the whole country, with a participation rate of $98.9 \%$. In order to eliminate the gap between the treatment of basic medical insurance for urban and rural residents, the State Council issued "the State Council's Opinions on the Integration of the Basic Medical Insurance System for Urban and Rural Residents" in January 2016, calling for the integration of the basic medical insurance system to establish a unified basic medical insurance system for urban and rural residents. When it comes to basic medical insurance system for urban and rural residents, it is still called "new rural cooperative medical insurance" in most cases. Meanwhile, for migrant workers, "new rural cooperative medical insurance" is more appropriate. Therefore, we still take "new rural cooperative medical insurance" as the topic to study the influence of new rural cooperative medical insurance on the household consumption of migrant workers.

In the past, many scholars have done a lot of research on NCMS, the results show that NCMS significantly improves the health level of participants, improves the "sick but not cured" condition of participants (Cheng \& Zhang, 2012), and can effectively increase the utilization of farmers' health services (Wagstaff, Lindelow, Gao, Xu, \& Qian, 2009; Gao, 2010), but the impact on middle and low income participants is not significant (Li, Wang, \& Lin, 2012), this confirms the positive effect of the NCMS. However, as most migrant workers belong to the middle and low-income groups, the actual utility of NCMS for migrant workers needs more consideration. In terms of the study on the welfare effect of NCMS, the degree of recognition and satisfaction of farmers to NCMS are common (Tian, Hou, \& Dong, 2010; Zhao, Yu, \& Yue, 2012; Yu, 2012), while the farmers' satisfaction with NCMS mainly depends on the benefit level of the farmers, the recognition degree of NCMS and the rationality of the system's own design (Chen \& Zhao, 2012; Yu, 2013), it indicates that there may be some problems in the process of promotion and publicity of NCMS or its system itself. The system design itself has strong regional segmentation and non-portability, the complex off-site reimbursement procedures and the non-joint between regions increase the difficulties of reimbursement for migrant workers (Ning \& Liu, 2014), which weakens the effect of the NCMS on reducing the future uncertain expenditure of migrant workers to some extent. Based on the theory of social exclusion, Li (2018) proposed that accessibility of NCMS to migrant workers is low, and migrant workers are still in the "crack " of medical assistance in urban and rural areas.

Previous studies on the consumption utility of the NCMS have focused on farmers as a whole, and the results are controversial. Some studies have confirmed that participating in the NCMS reduces household savings (Cheung \& Padieu, 2015) and promotes farmers' consumption (Bai \& Wu, 2014; Zhao, 2019), affirms the stimulating effect on farmers' consumption; Xiong and Li (2017) used the 2011 "China Health and Nutrition Survey", the study found that NCMS cannot fundamentally improve the consumption level of low-income people; Some scholars also have reached the conclusion that NCMS could suppress consumption (Su, Li, \& Wang, 2013). Therefore, the consumption utility of the NCMS needs to be further studied. At the same time, the existing literature on migrant workers as the object of consumption research tend to social insurance ( $\mathrm{Lu}, 2014)$ and commercial health insurance (Wen, $\mathrm{Li}, \&$ Zhou, 2019) mainly, the empirical research on the impact of NCMS on the consumption of migrant workers is relatively lacking, Liu \& Tsegai (2011) had put forward the need to make further research on migrant workers.

To sum up, this paper, by using China Migrants Dynamic Survey (CMDS), based on the precautionary savings theory, aims to analyze the benefits of the NCMS for migrant workers by exploring the influence of the NCMS to consumption for migrant workers, and put forward reasonable policy suggestions based on the shortcomings of the NCMS. This paper has the following innovation and practical significance: First, the research object is novel, focusing on the study of migrant workers, filling the vacancy in the existing literature about the influence of the NCMS on the consumption of migrant workers. The NCMS is the basic medical insurance specially created by our government for farmers, which is closely related to the consumption of migrant workers. The consumption of migrant workers not only reflects the welfare level of urban development enjoyed by migrant workers, but also relates to the deep-seated problems such as the optimization of China's consumption system and high-quality economic growth. Therefore, it is of great theoretical and practical significance to study the influence of the NCMS on the consumption of migrant workers. Second, this paper makes a further analysis of migrant workers, a special group, through rigorous heterogeneity analysis, deeply studies the NCMS mechanism and puts forward differentiated 
insurance policy suggestions which may be conducive to improving the NCMS. Thirdly, this paper also analyze the psychological needs of migrant workers, discusses the influence of social integration degree on the consumption of migrant workers' families, it may provide a new way to study the consumption utility of migrant workers in the future.

\section{Data Source and Variable Description}

\subsection{Data Source and Processing}

The micro-data used in this article is from the 2017 China Migrants Dynamic Survey by National Health Commission of China, which uses a layered, multi-stage, and proportional to the scale PPS method, covering 31 provinces (regions, cities) across the country and Xinjiang Production and Construction Corps where floating population is concentrated. The contents of the survey include basic information of the floating population and their family members, the scope and trend of migration, employment and social security, income and expenditure and residence, children migration and education. In addition, the macro data is from the 2018 China City Statistical Yearbook and the National Economics Macroeconomic and Real Estate Database.

Migrant workers, refer to workers who have their household registration in the countryside, enter the urban area to engage in non-agricultural work for 6 months or more, and have their habitual residence in the urban area, with non-agricultural income as the main income. We draw on the existing research methods to process the data through the following steps: First, according to the definition of migrant workers, the urban household registration floating population in the actual survey is excluded, and only the agricultural migrant population sample is retained. Meanwhile, samples flowing for non-economic reasons is excluded, only retain samples of migrant workers and doing business; Second, in order to make the data more representative of the migrant worker group, exclude observations from junior college and above; Third, due to the limitation of macro data, a few regional observations that lack macro data on house prices and urban GDP, are excluded, with some abnormal values and missing values. In the end, there were 79,461 valid observations.

\subsection{Variable Setting and Descriptive Statistics}

\subsubsection{The Explanatory Variable}

Annual Per Capita Consumption of Migrant Workers' Families, household consumption in short, refers to the annual per capita consumption of all family members in the current place of residence. Because the data of the survey is the average monthly household expenditure, multiply by 12 to convert it into annual expenditure in order to match the macro data. In addition, some members of the family are covered by the employment unit in the current place of residence. In order to prevent underestimation of household consumption and household income, the converted amount of the employment unit is included in the household consumption and household income.

\subsubsection{The Core Explanatory Variable}

New rural cooperative medical insurance (NCMS) is a dummy variable. Because in 2017, some cities have already begun to implement the basic medical insurance system for urban and rural residents (BMIS), which is the integration of basic medical insurance for urban residents and the farmers. Therefore, if migrant workers purchase either NCMS or BMIS, they are deemed to have purchased the NCMS. Among the valid sample, 66,827 observations have purchased NCMS and 12,796 have not. We make statistics on the age, sex, migration range, and number of left-behind children of the rural migrant workers who have been insured in NCMS.

Table 1. Participation distribution and participation rate

\begin{tabular}{lccc}
\hline & & $\begin{array}{c}\text { Participation } \\
\text { distribution }\end{array}$ & participation rate \\
\hline \multirow{3}{*}{ Age } & $15 \sim 30$ & $29.23 \%$ & $84.1 \%$ \\
& $30 \sim 45$ & $47.91 \%$ & $82.9 \%$ \\
& $45 \sim 60$ & $21.42 \%$ & $85.7 \%$ \\
\multirow{2}{*}{ Gender } & $>60$ & $1.44 \%$ & $88.0 \%$ \\
& Male & $57.97 \%$ & $84.3 \%$ \\
& Female & $42.03 \%$ & $83.4 \%$ \\
\hline
\end{tabular}




\begin{tabular}{lccc}
\hline \multirow{2}{*}{ Migration range } & Cross-province flow & $51.65 \%$ & $82.4 \%$ \\
& Cross-city flow & $29.42 \%$ & $83.6 \%$ \\
\multirow{2}{*}{ Number of left-behind children } & Cross-region flow & $18.93 \%$ & $89.2 \%$ \\
& $0 \sim 1$ & $92.32 \%$ & $83.6 \%$ \\
& $\geq 2$ & $7.68 \%$ & $88.0 \%$ \\
\hline
\end{tabular}

As is shown in the table, the participation rate of NCMS is high, all of which are above $80 \%$. In all ages, the participation rate of middle-aged migrant workers is relatively low. In terms of the scope of migration, as the scope increases, the rate of insurance participation decreases, which is likely to be related to high reimbursement costs; In terms of left-behind children, migrant workers with a large number of left-behind children are more willing to participate in insurance.

\subsubsection{Other Control Variables}

In addition to the core explanatory variables, we also control a series of variables that may affect the NCMS purchase intention and the household consumption of migrant workers, such as individual characteristic variables, family characteristic variables, and city macro characteristic variables. The definitions of the variables are shown in Table 2.

Table 2. Variable settings and definition

\begin{tabular}{|c|c|}
\hline Variable & Definition \\
\hline \multicolumn{2}{|l|}{ Explained variable } \\
\hline $\operatorname{Ln}(\mathrm{Y})$ & Annual household per capita consumption (yuan) logarithm \\
\hline \multicolumn{2}{|l|}{ Core explanatory variable } \\
\hline NCMS & Dummy variable, whether to buy NRCMS, yes $=1$, no $=0$ \\
\hline \multicolumn{2}{|l|}{ Other control variables } \\
\hline \multicolumn{2}{|l|}{ Individual characteristic variable } \\
\hline Future revenue forecast & $\begin{array}{l}\text { Whether to have any difficulty in doing business or finding a stable } \\
\text { job. If not, the future income is expected to be stable. Unstable }=1 \text {, } \\
\text { stable }=0\end{array}$ \\
\hline Age & The age of the migrant workers. \\
\hline Nation & Dummy variables, the Han nationality $=1$, other nationalities $=0$ \\
\hline Male & male $=1$, female $=0$ \\
\hline Education years & The education years of the migrant workers \\
\hline Marriage & Married $=1$, others $=0$ \\
\hline Health & $\begin{array}{l}\text { Measured by whether to have any illness (injury) in the past year. If } \\
\text { not, it is deemed to be healthy. Yes }=1, \mathrm{No}=0 \text {. }\end{array}$ \\
\hline Other medical insurance & $\begin{array}{l}\text { Dummy variable, if participating in other social health insurance, } \\
\text { the value is } 1 \text {, otherwise it is } 0\end{array}$ \\
\hline House property & Yes $=1$, No $=0$ \\
\hline Flow years & The time of flowing, in years. \\
\hline Cross-province flow & Migrant workers come from outside the province, Yes $=1$, others $=0$ \\
\hline Cross-city flow & $\begin{array}{l}\text { Migrant workers come from within the same province and outside } \\
\text { the city, Yes }=1 \text {, others }=0\end{array}$ \\
\hline State-owned enterprise & Migrant workers work in state-owned enterprises. $\mathrm{Yes}=1, \mathrm{No}=0$ \\
\hline Private enterprise & Migrant workers work in private enterprise. $\mathrm{Yes}=1, \mathrm{No}=0$ \\
\hline Foreign-owned enterprise & $\begin{array}{l}\text { Migrant workers work in foreign-owned enterprise. Yes }=1 \text {, } \\
\text { No }=0\end{array}$ \\
\hline
\end{tabular}




\begin{tabular}{ll}
\hline Family characteristic variable & \\
Ln $(\mathrm{HI})$ & Logarithm of annual household income \\
Family size & Number of people living in the same city \\
Spouse relocation & Dummy variable. Yes $=1$, No=0 \\
Number of left-behind children & Number of left-behind children under 16 years \\
\hline City macro characteristic variables & \\
Ln (HP) & Logarithm of house price in current living city \\
Ln (GDP) & Logarithm of GDP per capita \\
\hline
\end{tabular}

\subsubsection{Self-Selection and Mean Test}

For migrant workers, there is a greater possibility of self-selection in purchasing NCMS. NCMS must be purchased and reimbursed at the place of household registration. In some areas, Off-site reimbursement mechanism have been implemented. However, due to high pay lines and complicated procedures, migrant workers can rarely reimburse successfully. Therefore, migrant workers with long migration distances and long migration time have lower willingness to buy NCMS. At the same time, migrant workers' families with poor health and many left-behind children have a higher willingness to purchase. In order to estimate whether the purchasing group and the non-purchasing group have a large difference, which indicates selection bias, we do the variance test and mean tests on two groups. Because the sample size is large, the sample mean approximately obeys the normal distribution. The descriptive statistics, variance homogeneity test and the mean test are performed in Table 3.

Table 3. Descriptive statistics and means test

\begin{tabular}{|c|c|c|c|c|c|c|}
\hline \multirow{2}{*}{ Variable } & \multicolumn{2}{|c|}{$\mathrm{NCMS}=1$} & \multicolumn{2}{|c|}{$\mathrm{NCMS}=0$} & \multirow{2}{*}{$\begin{array}{c}\text { Variance } \\
\text { test }\end{array}$} & \multirow{2}{*}{ Mean test } \\
\hline & mean & $\mathrm{sd}$ & mean & sd & & \\
\hline $\operatorname{Ln}(\mathrm{Y})$ & 9.442 & 0.605 & 9.589 & 0.604 & $\mathrm{y}$ & $-0.147 * * *$ \\
\hline $\operatorname{Ln}(\mathrm{HI})$ & 13.647 & 0.541 & 13.729 & 0.559 & $\mathrm{n} * * *$ & $-0.082 * * *$ \\
\hline Family size & 3.275 & 1.156 & 3.159 & 1.159 & $\mathrm{y}$ & $0.116^{* * *}$ \\
\hline Spouse relocation & 0.106 & 0.308 & 0.094 & 0.291 & $\mathrm{Y}$ & $0.013 * * *$ \\
\hline Num. of left-behind children & 0.291 & 0.631 & 0.237 & 0.560 & $\mathrm{y}$ & $0.054 * * *$ \\
\hline Other medical insurance & 0.072 & 0.258 & 0.656 & 0.475 & $\mathrm{n} * * *$ & $-0.584 * * *$ \\
\hline Male & 0.580 & 0.494 & 0.564 & 0.496 & $\mathrm{y}$ & $0.016^{* * *}$ \\
\hline Age & 37.399 & 10.012 & 36.931 & 9.525 & $\mathrm{y}$ & $0.468 * * *$ \\
\hline Nation & 0.920 & 0.271 & 0.930 & 0.255 & $\mathrm{y}$ & $-0.010 * * *$ \\
\hline Education years & 8.898 & 2.304 & 9.384 & 2.324 & $\mathrm{y}$ & $-0.486 * * *$ \\
\hline Marriage & 0.862 & 0.345 & 0.832 & 0.374 & $\mathrm{n} * * *$ & $0.031 * * *$ \\
\hline Future revenue forecast & 0.559 & 0.496 & 0.697 & 0.459 & $\mathrm{y}$ & $-0.138 * * *$ \\
\hline Health & 0.475 & 0.499 & 0.490 & 0.500 & $\mathrm{y}$ & $-0.015^{* * *}$ \\
\hline House property & 0.174 & 0.379 & 0.266 & 0.442 & $\mathrm{n} * * *$ & $-0.092 * * *$ \\
\hline Flow years & 6.231 & 5.983 & 7.622 & 6.612 & $\mathrm{n} * * *$ & $-1.391 * * *$ \\
\hline Cross-province flow & 0.516 & 0.500 & 0.577 & 0.494 & $\mathrm{y}$ & $-0.061 * * *$ \\
\hline Cross-city flow & 0.294 & 0.456 & 0.303 & 0.459 & $\mathrm{y}$ & -0.009 \\
\hline State-owned enterprise & 0.016 & 0.127 & 0.062 & 0.241 & $\mathrm{n} * * *$ & $-0.046 * * *$ \\
\hline Private enterprise & 0.232 & 0.422 & 0.321 & 0.467 & $\mathrm{n} * * *$ & $-0.089 * * *$ \\
\hline Foreign-owned enterprise & 0.024 & 0.154 & 0.084 & 0.278 & $\mathrm{n} * * *$ & $-0.060 * * *$ \\
\hline Ln (HP) & 9.070 & 0.582 & 9.283 & 0.611 & $\mathrm{n} * * *$ & $-0.213^{* * *}$ \\
\hline Ln (GDP) & 11.387 & 0.439 & 11.519 & 0.398 & $\mathrm{y}$ & $-0.133 * * *$ \\
\hline
\end{tabular}

Note: y means homogeneity of variance, $\mathrm{n}$ means significant difference in variance; $* * *, * *, *$ indicate significant at $10 \%, 5 \%$, and $1 \%$ levels, respectively, same below. 
The test results show that there are significant differences in individual characteristic variables, family characteristic variables, and city characteristic variables between purchasing migrant workers and non-purchasing migrant workers. No significant difference between two group in cross-city flow variable, because usually, the implementation of policies related to the NCMS is issued by the provincial government. In all, there is a certain selection error problem in the sample data.

\section{Model}

\subsection{Ordinary Least Squares (OLS) Regression}

In order to explore the impact of NCMS on the household consumption of migrant workers, OLS model is used as the benchmark model in this paper to compare the difference in household consumption between participating and non-participating migrant workers. The model is set as follows:

$$
\operatorname{Ln}\left(Y_{i}\right)=\beta_{0}+\beta_{1} N C M S_{i}+\sum \lambda_{k} X_{i k}+\gamma u_{i}+\varepsilon_{i}
$$

Where, $i$ represent individual migrant workers, $\beta_{0}, \beta_{1}, \lambda_{k}, \gamma$ are the parameters to be estimated; $\operatorname{Ln}\left(Y_{i}\right)$ is the explained variable, indicate the household consumption of peasant workers (take logarithm); NCMS is the binary variable of whether to participate in NCMS, NCMS $=1$ means to participate, NCMS=0 means not to participate; $X_{i k}$ represents a range of control variables, including individual characteristic, family characteristic, and city characteristic; $u_{i}$ represents the dummy variable representing of fixed provincial (municipal) district; $\varepsilon_{i}$ is the interference term, indicating other unobservable factors.

\subsection{Propensity Score Matching Method (PSM) Regression}

Using OLS regression equation to estimate the impact of NCMS on the household consumption of migrant workers, there is an endogenous problem caused by self-selection in selective bias. As shown in the results of the difference test between groups in Table 3, there is a significant difference between the migrant workers who buy NCMS (treatment group) and the migrant workers who do not buy NCMS (control group), and the migrant workers decides whether to buy NCMS based on their own situation. For example, the poor health of migrant workers, the greater demand for medical services, will be more inclined to buy NCMS. If the self-selection of migrant workers is ignored, the estimation results may have some bias.

In view of the above problems, the propensity score matching method is adopted to further estimate the impact of NCMS on the household consumption of migrant workers. This method mainly compares the treatment group and the control group with the similar observable variables by matching the propensity score, so as to solve the selection bias and the endogenous problems. Its basic operation is as follows: firstly, a series of control variables in the OLS regression model are selected as covariates in the propensity score matching method to construct the probability model of NCMS participating in decision-making, logit regression is used to predict the probability of each migrant worker buying NCMS (NCMS=1), and the propensity score (pscore) is obtained. Then the propensity score is used to match the samples by means of nearest neighbor matching, radius matching, kernel matching and so on. Finally, based on the matched samples of the treatment group and the control group, the average effect of the treatment group (ATT), that is, the average impact of the purchase of NCMS on household consumption, can be calculated. The general expression is:

$$
\begin{aligned}
A T T & =E\left[\left(\ln Y_{1}-\ln Y_{0}\right) \mid N C M S=1\right] \\
& =E\left\{E\left[\left(\ln Y_{1}-\ln Y_{0}\right) \mid N C M S=1\right], p(X)\right\} \\
& =E_{p(X) \mid N C M S=1}\left\{E\left[\ln Y_{1} \mid N C M S=1, p(X)\right]-E\left[\ln Y_{0} \mid N C M S=0, p(X)\right]\right\}
\end{aligned}
$$

In the above formula, $\ln Y_{1}, \ln Y_{0}$ represent the household consumption level of migrant workers who buy NCMS and those who do not buy NCMS; $p(X)=\operatorname{Pr}(N C M S=1 \mid X)$ is the probability that each migrant worker in the sample buys NCMS.

\section{Empirical Analysis and Results}

\subsection{OLS Regression}

We first perform OLS regression on the benchmark model. The results are shown in Table 4. Regression (1) controls a series of control variables to explore the impact of each explanatory variable on the household consumption. 
Regression (2) has further control of regional effects, which controls differences in price levels, history, and culture among regions. In order to prevent the heteroscedasticity from affecting the accuracy of the standard error of the coefficients, robust regression is used to report the accurate standard error.

Table 4. Benchmark model OLS regression results

\begin{tabular}{|c|c|c|c|c|}
\hline \multirow{2}{*}{ Variable } & \multicolumn{2}{|c|}{ Regression (1) } & \multicolumn{2}{|c|}{ Regression (2) } \\
\hline & Coefficient & $\mathrm{Sd}$ & Coefficient & $\mathrm{Sd}$ \\
\hline NCMS & $-0.023 * * *$ & 0.0052 & $-0.027 * * *$ & 0.005 \\
\hline $\operatorname{Ln}(\mathrm{HI})$ & $0.631 * * *$ & 0.0048 & $0.630 * * *$ & 0.005 \\
\hline Family size & $-0.241 * * *$ & 0.0020 & $-0.244 * * *$ & 0.002 \\
\hline Spouse relocation & $0.010^{* *}$ & 0.0049 & $0.016 * * *$ & 0.005 \\
\hline Num. of left-behind children & $-0.015 * * *$ & 0.0029 & $-0.011 * * *$ & 0.003 \\
\hline Other medical insurance & $0.037 * * *$ & 0.0055 & $0.032 * * *$ & 0.006 \\
\hline Age & $-0.003 * * *$ & 0.0002 & $-0.003 * * *$ & 0.000 \\
\hline Nation & $0.016 * * *$ & 0.0060 & $0.024 * * *$ & 0.006 \\
\hline Education years & $0.007 * * *$ & 0.0008 & $0.005 * * *$ & 0.001 \\
\hline Marriage & $-0.230 * * *$ & 0.0065 & $-0.226^{* * *}$ & 0.006 \\
\hline Future revenue forecast & $-0.056 * * *$ & 0.0034 & $-0.049 * * *$ & 0.003 \\
\hline Health & $0.025 * * *$ & 0.0031 & $0.029 * * *$ & 0.003 \\
\hline House property & $0.072 * * *$ & 0.0042 & $0.078 * * *$ & 0.004 \\
\hline Flow years & $0.002 * * *$ & 0.0003 & $0.003 * * *$ & 0.000 \\
\hline Cross-province flow & $-0.084 * * *$ & 0.0047 & $-0.057 * * *$ & 0.005 \\
\hline Cross-city flow & $-0.016 * * *$ & 0.0046 & $-0.017 * * *$ & 0.005 \\
\hline State-owned enterprise & $0.044 * * *$ & 0.0103 & $0.0447 * * *$ & 0.010 \\
\hline Private enterprise & $0.018 * * *$ & 0.0038 & $0.023 * * *$ & 0.004 \\
\hline Foreign-owned enterprise & $-0.019 * * *$ & 0.0092 & $-0.020 * * *$ & 0.009 \\
\hline Ln (HP) & $0.045^{* * *}$ & 0.0038 & $0.074 * * *$ & 0.006 \\
\hline Ln (GDP) & $0.010 * *$ & 0.0047 & 0.000 & 0.006 \\
\hline Constant & $1.372 * * *$ & 0.0673 & $1.177 * * *$ & 0.082 \\
\hline Region fixed effect & Uncontrolled & & Controlled & \\
\hline Num. of observations & 79,461 & & 79,802 & \\
\hline $\mathrm{R}^{2}$ & 0.4839 & & 0.4909 & \\
\hline
\end{tabular}

In regression (1), the coefficient of NCMI insurance is -0.023 , and it is highly significant at a significance level of $1 \%$, indicating that the purchasing of NCMI has a suppressive effect on the household consumption of migrant workers. After further controlling the regional effect in regression (2), the coefficient of NCMI was -0.027 , and the inhibitory effect increased, which was still highly significant. The OLS regression result shows that when controlling other characteristic variables, NCMI reduces the household consumption of migrant workers by $2.7 \%$. The NCMI pays premiums on a household basis. Although the premiums per capita are low, the number of migrant workers' families is large. Fixed premium expenditure has a crowding-out effect on consumption. Due to difficulties in reimbursement, complicated approval methods, and high reimbursement costs in other places, the NCMI cannot effectively avoid the risk of uncertain medical expenditures for migrant workers. Migrant workers still need to save consumption to increase preventive savings. In the following, we will discuss further the inhibition effect of the NCMI on consumption.

\subsection{Propensity Score Matching Method}

Based on the previous analysis, the impact of NCMS for migrant workers household consumption will be biased under the selection bias and endogenous interference. Therefore, the propensity score matching method was used to 
re-estimate the sample.

To identify the actual effect changes brought by participation in NCMS, the following two steps are mainly adopted. First, to investigate the household consumption of rural migrant workers without participating NCMS, that is constructing a counterfactual situation. Second, the household consumption of migrant workers under the above counterfactual situation is compared with household consumption of migrant worker after participating in the NCMS. Since the above counterfactual situation cannot be observed, in the propensity score matching method, the logit model is established by introducing a series of covariates to estimate the propensity score, and the more similar samples from the control group are matched according to the estimated tendency score for comparison.

First check the quality of the match. As shown in Table 5, after matching by different methods, basically all the data are within the range of common values, so the sample loss is small in the matching process. Before matching, the mean standard deviation of all observed variables was 14.2, and after matching by different methods, the mean standard deviation narrowed to 4.8-6.4. At the same time, the re-estimated Pseudo R2 value after matching is very small, with a large decrease compared to the value before matching. This indicates that after matching, there is no significant difference in the distribution of the variables between the participating migrant workers and the non-participating migrant workers, and the matching process balances the data well. And the distribution map of propensity score density before and after matching (Figure 1.) further intuitively reflects the good effect of matching.

Table 5. Quality of different matching methods monitored different indicators

\begin{tabular}{lcccc}
\hline \multicolumn{1}{c}{ Sample } & Off support & On support & Pseudo R2 & Mean Bias \\
\hline Before matching & & & 0.32 & 14.2 \\
\hline After matching & & & & \\
1:1 nearest neighbor matching & 145 & 79,316 & 0.022 & 4.8 \\
1:4 nearest neighbor matching & 145 & 79,316 & 0.025 & 5.4 \\
1:4 nearest neighbor matching within caliper & 145 & 79,316 & 0.025 & 5.4 \\
Radius matching & 145 & 79,316 & 0.029 & 5.6 \\
Kernel Matching & 145 & 79,316 & 0.04 & 6.4 \\
Local Linear Matching & 145 & 79,316 & 0.022 & 4.8 \\
\hline
\end{tabular}

Note: In order to avoid sample loss, the nearest neighbor matching method takes the sampling with replacement; In radius matching, the radius is 0.01 .
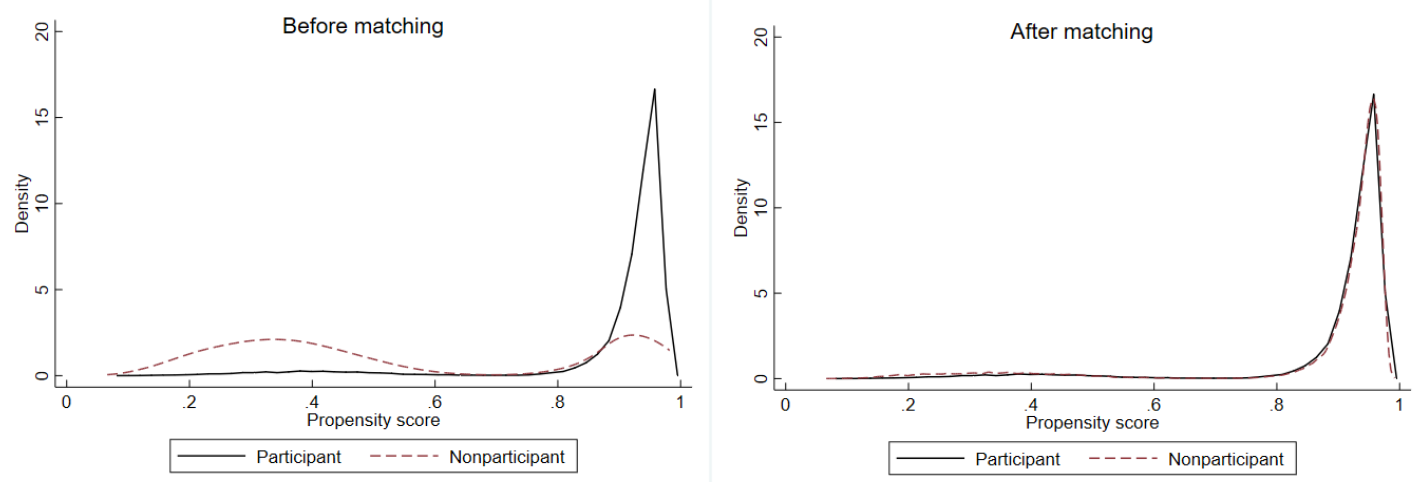

Figure 1. Propensity score density distribution map - local linear regression matching before and after

The ATT results of NCMS on household consumption of migrant workers calculated by different matching methods are shown in Table 6.

The data show that no matter which matching method is adopted, the purchase of NCMS has a significant negative effect on the household consumption of migrant workers (1\% significance level). Among them, the ATT value 
estimated by the 1:4 nearest neighbor matching method and 1:4 nearest neighbor matching within caliper method is the minimum, which is -0.0310 , while estimated result of the kernel matching method is the largest, which is -0.051 3. This result is consistent with the previous OLS regression, indicating that migrant workers did reduce their household consumption expenditure after purchasing NCMS.

Table 6. Results of the different preferences matching method

\begin{tabular}{|c|c|c|c|c|c|}
\hline Matching method & $\begin{array}{l}\text { Sample size of } \\
\text { treatment group }\end{array}$ & $\begin{array}{l}\text { Sample size of } \\
\text { control group }\end{array}$ & ATT & Standard error & T statistic \\
\hline $\begin{array}{l}1: 1 \text { nearest neighbor } \\
\text { matching }\end{array}$ & & & $-0.0379 * * *$ & 0.0131 & -2.90 \\
\hline $\begin{array}{l}\text { 1:4 nearest neighbor } \\
\text { matching }\end{array}$ & & & $-0.0310 * * *$ & 0.0108 & -2.87 \\
\hline $\begin{array}{l}1: 4 \text { nearest neighbor } \\
\text { matching within } \\
\text { caliper }\end{array}$ & 66,693 & 12,728 & $-0.0310 * * *$ & 0.0108 & -2.87 \\
\hline Radius matching & & & $-0.0372 * * *$ & 0.0099 & -3.77 \\
\hline Kernel Matching & & & $-0.0513^{* * *}$ & 0.0094 & -5.48 \\
\hline Local Linear Matching & & & $-0.0350^{* * *}$ & 0.0131 & -2.68 \\
\hline
\end{tabular}

Note: To avoid sample loss, the nearest neighbor matching method takes sampling with replacement; in radius matching, the radius is 0.01 .

\section{Further Analysis and Test}

\subsection{Analysis of the Mechanism of Inhibition Effect}

The reasons for the decline in consumption of migrant workers by purchasing NCMS are related to the crowding-out effect of consumption and increase in preventive savings.

The NCMS takes the family as a unit to ensure the registration, which is a fixed amount of expenditure for migrant workers, and causes a certain "squeezing" of other aspects of consumption. Because of the limitation of reimbursement, migrant workers who are migrating out must pay a large amount of medical expenses first, and bear the time, money and other costs when returning to the place of domicile for payment. At the same time, the migration directions of migrant workers are usually to cities or provinces with better economic development and higher wages. These cities also have higher price levels and higher medical consumption levels. Migrant workers are likely to pay more expensive medical services than in their own place of domicile.

Therefore, the migrant workers that purchases NCMS increases preventive savings to advance the large medical expenses required by themselves or family members when ill. Increasing savings also means reducing daily expenses and other consumption.

In order to verify the effect of purchasing the NCMS on consumption, we further explore the marginal consumption propensity of purchasing migrant workers and non-purchasing migrant workers. Take the amount of household consumption of migrant workers as the explanatory variable and annual household income as the core explanatory variable, as shown in Table 7. As is shown in the table, the marginal propensity of consumption of purchasing migrant workers is higher than that of non-purchasing migrant workers. This further illustrates that the willingness of non-purchasing migrant workers is higher, and the purchasing migrant workers increase preventive reserves.

Table 7. The impact of purchasing NCMS on marginal consumption tendency

\begin{tabular}{lcc}
\hline & NCMS $=1$ & NCMS $=0$ \\
\hline Household income & $0.257 * * *$ & $0.330^{* * *}$ \\
Other variables & 0.0166 & 0.0441 \\
Region fixed effect & Controlled & Controlled \\
\hline
\end{tabular}




\subsection{Analysis of Relevant Policies}

Faced with the difficulty of reimbursement, some cities have begun to implement the "off-site reimbursement" policy, with the aim of making basic medical insurance truly benefit the migrant population from different places. The off-site reimbursement policy provides more convenient reimbursement options for migrant workers. It is no longer necessary to pay large medical expenses by themselves and wait for a long time, waste much time and energy to return to the household registration for reimbursement.

However, off-site reimbursement cannot effectively solve the problem and truly provide welfare for migrant workers. The NCMS off-site reimbursement pay line is high and the procedures are complicated. The NCMS are mostly coordinated at the county level. When reimbursement is made in different places, the procedures are complicated, and there are many approval procedures and is long approval cycle.

In addition to the complexity of reimbursement procedures, the special status of migrant workers also makes them vulnerable when they apply for reimbursement in other places. Based on the theory of social exclusion (Join, 1999), migrant workers are in a vulnerable group that is discriminated against or prejudiced by locals in the city. They are excluded from the guarantee system. It is not uncommon that migrant workers are suffocated or neglected, when they go to reimburse. Meanwhile, migrant workers who are discriminated against by locals or who do not love or care about the cities cannot obtain timely information about the welfare policy of basic medical insurance and have a low awareness of fighting for their rights. So, in reality, migrant workers in the role of urban marginalized people usually choose to pay medical fees in advance. After accumulating a certain number, they will be reimbursed to their domicile. Only when they return to their domicile will they get a sense of identity.

\subsection{Heterogeneous Discussion}

The previous article confirmed that the purchase of NCMS has a significant negative impact on the household consumption of migrant workers. Next, the group of migrant workers is further classified according to income level, age, and urban integration, and the impact of the NCMS on household consumption of different groups of migrant workers is explored.

\subsubsection{Impact on Migrant Workers With Different Incomes}

We classified migrant workers into low-income group (monthly average income of 3500 yuan and below), middle-income group (greater than 3500 yuan and no more than 8,000 yuan), and high-income group (8,000 yuan or more) according to their income tax standards based on the 2017 personal income tax classification. Table 8 shows the results of the regression of different income migrant workers. Among them, (1), (2), and (3) are the OLS regression results, and (4), (5), and (6) are the regressions after the propensity score matches.

Table 8. Heterogeneous discussion-classified by income

\begin{tabular}{lcccccc}
\hline & $(1)$ & $(2)$ & $(3)$ & $(4)$ & $(5)$ & $(6)$ \\
\cline { 2 - 6 } & \multicolumn{3}{c}{ OLS regression } & \multicolumn{3}{c}{ PSM regression } \\
\cline { 2 - 6 } & Low & Middle & High & Low & Middle & High \\
\hline \multirow{2}{*}{ NCMS } & $-0.0267 * * *$ & $-0.0250^{* * *}$ & -0.0378 & $-0.0348 * *$ & -0.0256 & -0.0808 \\
Other variables & 0.0070 & 0.0082 & 0.0246 & 0.0172 & 0.0186 & 0.0593 \\
Region fixed effect & Controlled & Controlled & Controlled & Controlled & Controlled & Controlled \\
\hline Sample size & Controlled & Controlled & Controlled & Controlled & Controlled & Controlled \\
$\mathrm{R}^{2}$ & 46,337 & 29,245 & 3,879 & 46,150 & 29,182 & 3,673 \\
\hline
\end{tabular}

Note: The samples adopt a local linear matching pairing method.

As can be seen from the table, in PSM regression, the impact of NCMS on middle- and high-income migrant workers is not significant. The reason may be that the premiums paid for the NCMS have a crowding-out effect on 
consumption. Because low-income migrant workers have lower incomes and the premium is a heavy burden on them, so they will be more autonomous in reducing expenditures and increasing savings to prevent unexpected expenditures. NCMS's premium is a relatively small expenditure for middle- and high-income migrant workers, so it has no significant impact on their consumption.

\subsubsection{Impact on Migrant Workers With Different Ages}

Considering that different ages of migrant workers may have large differences in consumption concepts, wealth accumulation, and health status, they are divided into the age scale of "under 30", "30-40", "40-50" and "over 50" group. From Table 9, it is clearly that whether after the OLS regression or the preference score matching regression, only in the migrant worker group under 30 years old, the NCMS's negative effect on household consumption is significant. The reason may be that younger migrant workers have less accumulated wealth, better health, and less medical expenditures. So, they gain less benefits from NCMI, and the "squeezing out" effect of premiums on consumption is significant.

Table 9. Heterogeneous discussion-classified by age

\begin{tabular}{lcccccccc}
\hline & $(1)$ & $(2)$ & $(3)$ & $(4)$ & $(5)$ & $(6)$ & $(7)$ & $(8)$ \\
\cline { 2 - 8 } & \multicolumn{9}{c}{ OLS regression } & & & \multicolumn{2}{c}{ PSM regression } & under 30 \\
\cline { 2 - 8 } & over 50 & $40-50$ & $30-40$ & under 30 & over 50 & $40-50$ & $30-40$ & $-0.0438^{* *}$ \\
NCMS & -0.0109 & -0.0241 & -0.0222 & $-0.0363 * * *$ & -0.0455 & -0.0033 & -0.0225 & -0.0224 \\
Other variables & 0.0202 & 0.0102 & 0.0088 & 0.0092 & 0.0476 & 0.0241 & 0.0225 & 0.0224 \\
Region fixed & Controlled & Controlled & Controlled & Controlled & Controlled & Controlled & Controlled & Controlled \\
effect & Controlled & Controlled & Controlled & Controlled & Controlled & Controlled & Controlled & Controlled \\
Sample size & 7,854 & 22,374 & 26,065 & 23,168 & 7,837 & 22,353 & 25,975 & 23,137 \\
$\mathrm{R}^{2}$ & 0.4406 & 0.4455 & 0.4998 & 0.4960 & & & & \\
\hline
\end{tabular}

\subsubsection{Impact on Migrant Workers With Different Degree of Urban Integration}

When migrant workers migrate to other places to work, because of unfamiliar living environments, large differences in living habits, and lack of sense of belonging and identity, it is difficult for them to integrate into the city. However, when migrant workers adapt to local life, with high urban integration, they are more likely to choose to settle or work for a long time. Conversely, if urban integration of migrant workers is low, they are more likely to return to their homes and choose a place with a higher sense of identity. For migrant workers with high degree of urban integration, the NCMS insured at the household registration has no way to effectively play a protective role for them.

We use the answer of migrant workers toward the social integration part of the questionnaire, to divide the migrant workers into high and low urban integration group. Migrant workers with a high degree of urban integration agree with the saying "I would like to be integrated into the local area" and "Local people are willing to accept me as one of them." As shown in Table 10, under the PSM regression, migrant workers with a high degree of urban integration cannot enjoy the welfare of the insurance when they buy the NCMS, which will squeeze out consumption.

Table 10. Heterogeneous discussion-classified by degree of urban integration

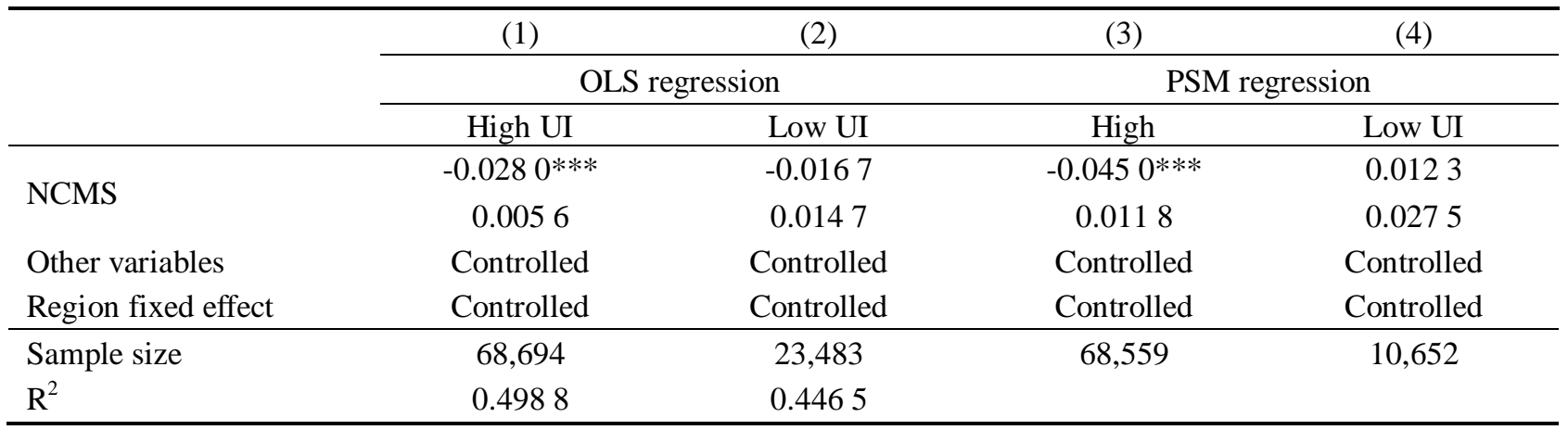




\subsection{Robustness Test}

In order to further test the reliability of the estimation results, we carried out robustness tests by eliminating special values, eliminating extreme values, and changing the matching methods. In terms of eliminating the extreme value, we take the converted amount of unit allowance for food and accommodation into the consumption and income of migrant workers when dealing with the logarithm variables of annual per capita consumption and income of migrant workers' families. In order to avoid the influence of different calculation criteria of the converted amount of unit allowance for food and accommodation on the variables, OLS regression (1) removed the samples which is food and accommodation provided by the place of work. As shown in Table 11, the coefficient of NCMS is -0.0301 , highly significant. Secondly, in order to avoid the special influence of municipalities directly under the Central Government, the OLS regression (2) removed the sample of migrant workers living in Beijing, Shanghai, Tianjin and Chongqing, and the coefficient obtained shows that the inhibiting effect of purchasing migrant workers on consumption is reduced, but still highly significant. In addition, in order to avoid the influence of the existence of extreme values on the sample, we also carried out a tail test by excluding the sample of top $2 \%$ and bottom $2 \%$ of consumer spending. The coefficient results of regression (3) have little change and are still consistent with former regression results. At the same time, by changing the matching method (regression (4)), the model processing is more rigorous, the variation range of coefficients is small, and the estimated coefficients are basically the same under different pairing methods. Through the above tests, it can be proved that the estimated results in this paper are reliable and robust.

Table 11. Robustness test

\begin{tabular}{lcccc}
\hline & $(1)$ & $(2)$ & $(3)$ & $(4)$ \\
\cline { 2 - 5 } & $\begin{array}{c}\text { No food and } \\
\text { lodging samples } \\
\text { included }\end{array}$ & $\begin{array}{c}\text { Excluding } \\
\text { municipalities }\end{array}$ & Tailing test & $\begin{array}{c}\text { Change the } \\
\text { matching method }\end{array}$ \\
\hline NCMS & $-0.0301^{* * *}$ & $-0.0253^{* * *}$ & $-0.0298^{* * *}$ & $-0.0310^{* * *}$ \\
Other variables & 0.0061 & 0.0057 & 0.0050 & 0.0108 \\
Fixed Area Effect & Controlled & Controlled & Controlled & Controlled \\
\hline Sample size & Controlled & Controlled & Controlled & Controlled \\
$\mathrm{R}^{2}$ & 61,892 & 70,413 & 77,944 & 79,316 \\
\hline
\end{tabular}

\section{Conclusion}

This article systematically analyzes the impact of the NCMS on household consumption of migrant workers by using the large sample microdata of the 2017 China Migrants Dynamic Survey by National Health Commission, using the ordinary least squares method and the propensity score matching method. The study found that compared with nonparticipating migrant worker families, the average household consumption of participating migrant worker families decreased by $3.5 \%$.

From the results of group regression, there is a significant difference in the impact of NCMS on household consumption of different groups of migrant workers.

The empirical results of this paper have important policy implications. Since the implementation of the NCMS in 2003, it has basically covered rural areas. Migrant worker is a very representative group of farmers but fail to benefit from the NCMS. This indirectly reflects that there is still room for improvement. Based on this conclusion, the following suggestions are made:

First, adopt differentiated insurance treatment policies for migrant workers with different income levels. For low-income migrant workers, a "NCMS Credit Card Mechanism" can be established to solve the problem. At the place where the migrant workers live, they can apply for a NCMS credit card from the local government's NCMS fund coordinating department or association with a certificate of participation, real-name certification, a city income certificate or a poverty certificate. When get ill, with the card, they consume medical services without advancing some reimbursable expenses. The credit card adopts an annual settlement system. When return to the participating place, migrant workers must apply for reimbursement and settlement. Through the credit card mechanism, the squeeze-out effect on the consumption and the heavy advancement burden of low-income migrant workers can be 
reduced, so that they can truly benefit from NCMS.

Second, appropriately adjust safeguard policies, such as pay line and reimbursement ratios. For off-site reimbursement, the pay line is high, the reimbursement ratio is low, and the procedure is cumbersome. Meanwhile, you must follow the hierarchical diagnosis and treatment system to get reimbursement. If the low-level hospital cannot meet the medical needs, the cost is an additional expense for migrant workers. For migrant workers, they will still face a heavy economic burden. Therefore, in order to better meet the needs of migrant workers, the payment line and reimbursement ratio of high-level hospitals can be appropriately adjusted.

Third, pay attention to the medical needs of the floating population, and introduce off-site insurance coverage. Combining the empirical results of the impact of NCMS on the consumption of migrant workers in different urban integration degrees and the significant positive impact of "expected future income" on consumption, we suggest that migrant workers with stable expected future incomes or high urban integration can be allowed to participate in NCMS in working place. The higher degree of urban integration means that migrant workers can integrate into the city psychologically and have the willingness to stay in the city for a long time, which can give full play to their productivity and create more value for the society. At the same time, their stable expected future income can promote consumption. Therefore, corresponding policies can be implemented. Migrant workers can apply for new NCMS in migrant cities, with long-term employment certificate issued by the employment unit, which avoid external factors such as difficulties in reimbursement from other places to offset the positive role of the NCMS, and also promote social harmony.

Fourth, strengthen publicity and raise farmers' awareness of NCMS. Migrant workers' awareness of NCMS compensation policies is often low, and their trust in NCMS is low, either. Meanwhile, most migrant workers have low education levels and lack access to information. Therefore, all regions should continue to improve the basic medical information platform. Special brochures can be distributed for reading before enrollment, and short message notifications can be used after important decision-making is performed, in order to benefits everyone. In addition, information exchange and information sharing should be strengthened between regions to reduce the barriers to reimbursement of migrant workers due to information gaps.

\section{Acknowledgements}

We acknowledge the research supports of Guangdong higher education teaching reform project "Research on the reform of case teaching of insurance course based on the cultivation of students' ability to analyze (2019-246)". Meanwhile, we also acknowledge the research project of degree and postgraduate education reform in Guangdong Province "Research on the teaching mode reform of management economics for postgraduates under the background of research university construction (2019JGXM49)". Finally, we acknowledge the research supports of Shantou university national fund project (NFC16009) and the teaching and research project "STU curriculum special fund for insurance course (FIN1004B)".

\section{References}

Bai, C., \& Wu, B. (2014). Health insurance and consumption: Evidence from China's new cooperative medical scheme. Journal of Comparative Economics, 42(2), 450-469.

Bairoliya, N., Canning, D., Miller, R., \& Saxena, A. (2018). The macroeconomic and welfare implications of rural health insurance and pension reforms in China. The Journal of the Economics of Ageing, 11, 71-92.

Chen, D., \& Zhao, L. F. (2012). The survey and test of farmers' satisfaction with the new rural cooperative medical system. Journal of Agrotechnical Economics, 10, 104-111.

Cheng, L. G., \& Zhang, Y. (2012). The new rural cooperative medical scheme: Financial protection or health improvement? Economic Research Journal, (1), 120-133.

Cheung, D., \& Padieu, Y. (2015). Heterogeneity of the effects of health insurance on household savings: Evidence from rural China. World Development, 66, 84-103.

Gao, M. T. (2010). New rural cooperative medical care and utilization of rural health services. World Economy, (10), 79-97.

Hubbard, R. G., Skinner, J., \& Zeldes, S. P. (1995). Precautionary saving and social insurance. Journal of Political Economy, 103(2).

Leland, H. E. (1968). Saving an uncertainty: The precaution. Quarterly Journal of Economics, 82, 465-473.

Li, X. J., Wang, Z. H., \& Lin, Z. P. (2012). Impact of new rural cooperative medical treatment on farmers' medical 
behavior and health—_ Analysis based on different income levels. World Economic Papers, (3), 58-75.

$\mathrm{Li}$, Y. J. (2018). The study on the construction of medical assistance system for migrant rural workers-Based on the theory of social exclusion. Journal of Guangxi Economic Management Cadre College of Economic and Management, 30(1), 6-11.

Liu, D., \& Tsegai, D. W. (2011). The New Cooperative Medical Scheme (NCMS) and its implications for access to health care and medical expenditure: Evidence from rural China. ZEF - Discussion Papers on Development Policy, 155.

Lu, H. Y. (2014). The effect of social insurance on household consumption of rural-urban migrants. Population \& Economics, 205(4), 33-42.

Ning, M. X., \& Liu, J. (2014). Study on the effects of new rural cooperative medical system on farmers' migratory workplace decisions. Collected Essays on Finance and Economics, 180(4), 41-46.

Propaganda department of the CPC central committee. (2018). Extracts from the Report of the 19th National Congress of the Communist Party of China. China, CN: the CPC central committee.

Su, C. H., Li, Q. Y., \& Wang, D. H. (2013). The influence of different basic medical insurance on Chinese residents' medical consumption-Based on the CHNS data. Research on Economics and Management, (10), 23-30.

Tian, X. J., Hou, J. L., \& Dong, Z. M. (2010). Farmers' comprehensive evaluation of the new rural cooperative medical system-Based on the survey of 916 farmers in 13 provinces. Chinese Rural Economy, (5), 86-96.

Wagstaff, A., Lindelow, M., Gao, J., Xu, L., \& Qian, J. C. (2009). Extending health insurance to the rural population: An impact evaluation of China's new cooperative medical scheme. Journal of Health Economics, 28, 1-19.

Wen, L., Li Q., \& Zhou, Z. P. (2019). Can commercial medical insurance promote rural migrant workers' consumption-An empirical research based on the dynamic monitoring survey data. Insurance Studies, (5), 81-96.

Xiong, B., \& Li, J. T. (2017). New cooperative medical scheme and consumption of rural residents. Finance \& Economics, (7), 64-76.

Yu, C. L. (2012). Performance evaluation on new type of rural cooperative medical care system. Statistical Research, 29(4), 92-97.

Yu, C. L. (2013). Personal feature, compensation mechanism and peasants' satisfaction of new rural cooperative medical scheme. Population \& Economics, 201(6), 101-110.

Zeldes, S. P. (1989). Consumption and liquidity constraints: An empirical investigation. The Journal of Political Economy, 97, 305-346.

Zhao, W. M. (2019). Does health insurance promote people's consumption? New evidence from China. China Economic Review, 53, 65-86.

Zhao, W. W., Yu, C. L., \& Yue, Z. (2012). Peasants' welfare experience and the welfare effects of new rural cooperative medical system. Population \& Economics, 191(2), 87-92.

Zhou, Q., \& Liu, G. E. (2016). The difference of benefits from health insurance: Based on the study of the local population and migrants. Nankai Economic Research, (1), 77-94. 